\title{
A clinical study of anemia in children aged 6 months -5 years in a tertiary care center, Bengaluru, Karnataka, India
}

\author{
Siva Saranappa ${ }^{1}$, Jennifer $\mathbf{W} \mathbf{u}^{2}$ \\ From ${ }^{1}$ Associate Professor, ${ }^{2}$ Postgraduate, Department of Pediatrics, Kempegowda Institute of Medical Sciences, Bengaluru, Karnataka, India
}

\begin{abstract}
Background: Anemia is the most commonly observed hematological diseases in children. The World Health Organization (WHO) has estimated that globally, 1.62 billion people are anemic, with the highest prevalence of anemia (47.4\%) among preschool-aged children. Of these 293 million children, 89 million live in India. Aim: This study aims to evaluate the factors causing anemia in children aged between 6 months and 5 years and its prevalence within this age group. Methods: This study is a prospective observational study conducted in KIMS Hospital, Bengaluru, Karnataka. A total of 200 children in the age group of 6 months-5 years with features of anemia or having hemoglobin $<11 \mathrm{~g} / \mathrm{dl}$ were included in the study for a duration of 18 months between January 2019 and June 2020 . Detailed history was recorded and examination findings were noted. The data collected were tabulated and statistically analyzed accordingly. Results: About $57.5 \%$ of the children with anemia fell between the age group of 6 months and 2 years and $42.5 \%$ of children were in the age groups of 2-5 years. A male predominance was seen (61\%) with male-to-female ratio of approximately $1.56: 1$. Most of the children were found to have mild (46\%) and moderate anemia (46\%) with only a minority $(8 \%)$ presenting with severe anemia. About $56.5 \%$ of the children had a normal nutritional status while $41 \%$ were malnourished and $2.5 \%$ had both wasting and stunting. Exclusive breastfeeding (for 6 months) history was present in 59\% of the children. These children belonged mostly to the upper lower (45\%) and lower middle (41\%) socioeconomic status. This study also showed anemia in children most commonly presented majorly with concurrent involvement of the respiratory system (31\%) followed by infectious diseases (30\%) and gastrointestinal disorders (23\%). Conclusion: The current study concludes that iron deficiency anemia is a multifactorial hematological disease. Learning about the predisposing risk factors can help to adopt the necessary precautions to prevent anemia in these children. Improving the nutritional status of the children by involving parents and counseling them regarding important feeding practices can help to prevent anemia.
\end{abstract}

Key words: Anemia, Iron deficiency, Malnutrition, Socioeconomic status, Under 5 years old

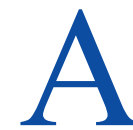

nemia is a global public health problem which affects both the developing and the developed countries, with higher prevalence in developing countries. It is defined as a reduction in hemoglobin $(\mathrm{Hb})$ by two standard deviations below the mean, based on age-specific norms or decrease in their oxygen-carrying capacity to meet physiologic needs, which may vary as per the age, sex, altitude, and pregnancy status. The World Health Organization (WHO) has estimated that globally, 1.62 billion people are anemic, with the highest proportion of anemia (47.4\%) among preschool-aged children. Of these 293 million children, 89 million live in India. National Family Health Survey (NFHS) done in 2005-2006 revealed that at least $80 \%$ of children in India aged between 12 and 23 months are anemic [1]. There are several potential causes of anemia in the context of

\section{Access this article online}

Received - 07 August 2021

Initial Review - 23 August 2021

Accepted - 20 September 2021

DOI: 10.32677/IJCH.2021.v08.i10.3067 the Indian population which include low nutritional iron and low Vitamin C intake; parasitic infections, such as hookworm and malaria. Nearly 47 million or four out of 10 children in India do not meet their full human potential because of chronic undernutrition or stunting. According to the further report, 38.4\% of children aged under-5 in India are stunted (too short for their age), while $21 \%$ suffer from wasting (weight is too low for their height). It is now a known fact that a high prevalence of anemia among under 5-year-old children arises from the combination of increased iron needs due to accelerated growth and development, and is mainly associated with diet which is poor in heme iron [2].

Exclusive breastfeeding is an important nutritional aspect for the child's growth and development [3]. The WHO and UNICEF have recommended that breastfeeding should be initiated within the $1^{\text {st }} \mathrm{h}$ of birth and exclusive breastfeeding should be continued for the first 6 months of life. From the age of 6 months, children should begin eating complementary foods while continuing

Correspondence to: Jennifer $\mathrm{Wu}, 2^{\text {nd }}$ floor, Mandara, $5^{\text {th }}$ Main Road, NR Colony, Basavanagudi, Bengaluru - 560 019, Karnataka, India. E-mail:wenu2010@gmail.com

(C) 2021 Creative Commons Attribution-NonCommercial 4.0 International License (CC BY-NC-ND 4.0). 
to breastfeed for up to 2 years and beyond [4], as the child has maximum brain growth and myelination in this period. Even though human milk has low iron content, it is better suited for needs of a growing infant, having much better bioavailability for iron than cow's milk [3]. When complimentary feeds are initiated by 5 or 6 months of age, breast milk supply reaches maximum and plateaus off subsequently with depletion of calcium and iron stores. If the complementary feeds are mostly vegetarian items and cow's milk, then there is risk of developing deficiency of calcium, iron, zinc, Vitamin A, folic acid, Vitamin C, and Vitamin B12 [3]. It is said that the baby is "biologically ready" to receive semi solids by 4- 6 months of age. Early weaning practices lead to contamination and infections because of unhygienic preparations and late weaning can lead to growth faltering and malnutrition. Hence, most children fall into the pit of malnutrition during the weaning and post-weaning phase [3].

Malnutrition being an important risk factor for causing anemia includes undernutrition (wasting, stunting, and underweight), inadequate intake of vitamins or minerals; overweight; and obesity resulting in diet-related non-communicable diseases. Around 45\% of deaths among children under-5 years of age have been linked to undernutrition. These mostly occur in low- and middle-income countries [5]. Poverty increases the risk of malnutrition. People who are poor are more likely to be affected by different forms of malnutrition [5]. Both point toward the importance of food security in the given population. Food security, as defined by the United Nations' committee on world food security, is all people, at all time, have physical, social, and economic access to sufficient, safe, and nutritious food that meets their food preferences and dietary needs for an active and healthy life [6]. Food security is a combination of three main elements: Food availability, food access, and food utilization [2].

Anemia also causes suppression of the immune system with increased tendency for infection, depression of cognitive function, growth, and psychomotor development, leading to difficulties in learning and reduced physical capacity [6]. Since it is a multifactorial condition, even the history of the patient is as important as the physical examination and laboratory tests. Looking at the condition from all its aspects will help reduce the disease burden in our state and country. The most common cause is said to be nutritional anemia, commonly iron deficiency. Therefore, the term iron deficiency anemia is being used synonymously with the term anemia in children. In Karnataka, NFHS-5 fieldwork was conducted from July 10, 2019, to December 11, 2019, by Nielsen India Pvt. Ltd. and an increase in anemia of children in the age group of 6 months -5 years was observed [1]. In Bangalore, a similar fieldwork also revealed an increase by $7.2 \%$ of children with anemia in the same age group [7].

\section{METHODS}

This is a prospective observational study conducted with 200 children aged 6 months -5 years over a time span of 18 months in KIMS Hospital, Bengaluru. The included children were evaluated and screened for anemia by hemoglobin estimation and other relevant investigations. This study was approved by the Institutional Ethics Committee of the institute and informed consent was obtained from the parents or the legal guardians of the children. The inclusion criteria were children aged between 6 months and 5 years with clinical features of anemia or with $\mathrm{Hb}<11 \mathrm{~g} / \mathrm{dl}$. Children on treatment or already diagnosed with anemia or unwilling to provide informed consent were excluded from the study.

The sample size of 200 was calculated using Open Epi software version 3, open-source calculation was done using the formula $4 \mathrm{PQ} / \mathrm{d}^{2}$ where $\mathrm{P}$ is the estimated prevalence $-49 \%$, $\mathrm{Q}=100-\mathrm{P}=52$, and $\mathrm{d}=$ (confidence level - acceptable margin of error for proportion being estimated $)=20 \%$ of P. Hence, the sample size $=9996 / 96.0=104$. According to the formula above, the total sample size was taken to be $\sim 100$ but after doubling effect, the total sample size of 200 was selected for more precision.

On admission, a detailed history with emphasis on current and past symptoms was taken, with importance to the nutritional status of the child, their socioeconomic status, and history of breastfeeding and weaning. Children selected for the study underwent hematological work-up including complete hemogram, peripheral blood smear, and red blood cell indices. Further workup, such as an iron profile, reticulocyte count, red cell distribution width, folic acid, and Vitamin B12 levels, was tested if required. Table 1 describes the WHO criteria for the diagnosis of anemia and the subdivision of anemia as per its severity [8].

The data were analyzed using the Chi-square test, a statistical test which is applied to sets of categorical data to evaluate any observed difference. $\mathrm{p}<0.05$ is considered as statistically significant.

\section{RESULTS}

The demographic profile of the study population is detailed in Table 2.

According to IAP classification of malnutrition and Waterlow's classification, it was also seen that $56 \%$ of the anemic children had normal nutritional status whereas $41 \%$ were underweight and a minor percentage $(2.5 \%)$ suffered from wasting and stunting. In our study also, the nutritional status of a child is being found highly correlated with the incidence of anemia $(p<0.001$, Table 2$)$. Mother's education status was also taken as a factor to compare the proportion of anemia (Table 2).

Table 1: The WHO criteria for the diagnosis of anemia and further division of the degree of anemia

\begin{tabular}{|c|c|c|c|c|}
\hline \multirow[t]{2}{*}{ Population } & \multirow{2}{*}{$\begin{array}{c}\text { Non-anemia } \\
\text { (Hb in } \\
\text { gm/dl) }\end{array}$} & \multicolumn{3}{|c|}{$\begin{array}{l}\text { Anemia as per the severity } \\
(\mathrm{Hb} \text { in } \mathrm{gm} / \mathrm{dl})\end{array}$} \\
\hline & & Mild & Moderate & Severe \\
\hline $\begin{array}{l}\text { Children } \\
\text { (age: 6-39 months) }\end{array}$ & $\geq 11$ & $11-11.9$ & $7-9.9$ & $<7$ \\
\hline $\begin{array}{l}\text { Children } \\
\text { (age: } 5--11 \text { years) }\end{array}$ & $\geq 11.5$ & $11-11.4$ & $8-10.9$ & $<8$ \\
\hline $\begin{array}{l}\text { Children } \\
\text { (age: } 12-14 \text { years) }\end{array}$ & $\geq 12$ & $11-11.9$ & $8-10.9$ & $<8$ \\
\hline
\end{tabular}


Table 2: The demographic profile of the study population

\begin{tabular}{|c|c|c|}
\hline Demographics & Frequency $($ total $=200)$ & Percentage \\
\hline \multicolumn{3}{|l|}{ Age } \\
\hline 6 months -2 years & 115 & 57.5 \\
\hline $2-5$ years & 85 & 42.5 \\
\hline \multicolumn{3}{|l|}{ Gender } \\
\hline Male & 122 & 61 \\
\hline Female & 78 & 39 \\
\hline \multicolumn{3}{|l|}{ Severity of anemia } \\
\hline Mild & 92 & 46 \\
\hline Moderate & 92 & 46 \\
\hline Severe & 16 & 8 \\
\hline \multicolumn{3}{|l|}{ Peripheral smear } \\
\hline Dimorphic & 5 & 2.5 \\
\hline Microcytic & 162 & 81 \\
\hline Normocytic & 33 & 16.5 \\
\hline \multicolumn{3}{|l|}{ Nutritional status } \\
\hline Normal & 113 & 56.5 \\
\hline Grade I malnutrition & 52 & 26 \\
\hline Grade II malnutrition & 15 & 7.5 \\
\hline Grade III malnutrition & 5 & 2.5 \\
\hline Grade IV malnutrition & 10 & 5 \\
\hline Wasting and stunting & 5 & 2.5 \\
\hline \multicolumn{3}{|l|}{ Mother's education } \\
\hline Postgraduate & 1 & 0.5 \\
\hline Graduate & 6 & 3 \\
\hline Secondary & 57 & 28.5 \\
\hline Primary & 102 & 51 \\
\hline Illiterate & 34 & 17 \\
\hline \multicolumn{3}{|l|}{ Socioeconomic status } \\
\hline Lower & 1 & 0.5 \\
\hline Upper-lower & 90 & 45 \\
\hline Lower-middle & 82 & 41 \\
\hline Upper-middle & 21 & 10.5 \\
\hline Upper & 6 & 3 \\
\hline \multicolumn{3}{|l|}{ Concurrent illness } \\
\hline $\begin{array}{l}\text { Central nervous } \\
\text { system }\end{array}$ & 5 & 2.5 \\
\hline Gastrointestinal & 46 & 23 \\
\hline Infectious diseases & 61 & 30.5 \\
\hline Renal & 11 & 5.5 \\
\hline Respiratory & 62 & 31 \\
\hline Others & 15 & 7.5 \\
\hline \multicolumn{3}{|l|}{ Exclusive breastfeeding } \\
\hline Till 6 months & 118 & 59 \\
\hline Less than 6 months & 82 & 41 \\
\hline
\end{tabular}

\section{DISCUSSION}

In our clinical study, anemia was observed to be prevalent in children between the age groups of 6 months and 2 years. Kanchana et al. [9] carried out a similar study but a higher number of anemic children were seen in the age group of 2-5 years (61\%) than the 6 months -2 years age group (39\%). Studies by Singh and Parihar [10] and Gebreweld et al. [11] done in Jammu and Kashmir and Ethiopia, respectively, showed a higher proportion of anemia in children below 2 years of age. The cause in this age group is commonly due to inadequate iron intake in the diet and the weaning practices which are undertaken. One example for this is excessive consumption of cow's milk before 6 months of age, which has low iron content and can lead to blood loss from milk protein colitis.

The proportion of anemia based on the gender was also discussed in literature. In our study, anemia was observed in higher proportion in males. However, in studies by Parkin and Maguire [12] and Gebreweld et al. [11], higher proportion of anemia was observed in females. Since no gender predominance was observed, it can be said that the iron deficiency anemia can occur equally in either male or female children.

Our study also compared the severity of anemia according to the WHO classification (Table 1). In the study by Kanchana et al. [9], higher proportion of moderate anemia was seen (46.8\%) along with $26.6 \%$ of children having mild anemia and $3.6 \%$ with severe anemia. In the same study, she also evaluated proportion of anemia based on the peripheral blood picture, with $45 \%$ having normocytic anemia, $37 \%$ with microcytic anemia, and $18 \%$ with dimorphic anemia. In a study conducted by Marol and Marol [13] in Haveri, Karnataka, $71(87.6 \%)$ out of a total 81 infants between the age groups of 3 and 6 months had anemia (69\% mild, $28 \%$ moderate, and $2.8 \%$ severe). Highest prevalence $(92.3 \%$ ) was observed at 3 months of age [13].

In our study, most of the peripheral blood pictures seen was microcytic blood picture (81\%) mostly suggestive of the diagnosis of iron deficiency anemia. Out of the 16 children with severe anemia, $5(31 \%)$ had a dimorphic blood picture which is due to nutritional vitamin B12 and folic acid deficiency. In a total of 108 children with moderate and severe anemia, further evaluation was done in children with clinical features of anemia and those with dimorphic peripheral blood picture. In children who were evaluated for iron deficiency anemia, serum levels of iron and ferritin were taken into account as they are sensitive markers. In all 18 children (100\%), serum iron was reduced along with reduced transferrin saturation levels. From the 25 children evaluated for serum ferritin, 15 children $(60 \%)$ had reduced levels while the other $10(40 \%)$ had normal ferritin levels. Serum ferritin indicates depletion of iron tissue stores hence it is a sensitive marker for iron deficiency anemia. It has reduced specificity as it is also an acute phase reactant that becomes elevated in response to inflammation.

In individual studies by Santos et al. [14] and Singh and Parihar [10], a correlation is seen between child's nutritional status and anemia. In his study, Singh and Parihar [10] also found majority of children $(58.33 \%)$ belonging to the underweight category. Nutrition is the most common cause of anemia in the age group of 6 months -5 years as iron stores present at birth usually is sufficient only during the first 6-9 months of life after which the iron stores start depleting. Hence if the nutrition is not 
adequate and rich in iron, it can lead to iron deficiency. Marol and Marol [13] mentioned in his study that delayed cord clamping (around 120-180 s) is associated with an improved iron status at 2-6 months of age. In a study done by Buck et al [15]. In Southeast Nigeria, concluded that breastfeeding for longer than 9.5 months was predictive of low to borderline $\mathrm{Hb}$ in $2-5$ years old children, hence indicating towards the importance of an appropriate weaning period. Children with low Hb levels were breastfed for a mean of 2.4 months longer than those children with normal $\mathrm{Hb}$. Therefore, longer breastfeeding was associated with lower $\mathrm{Hb}$ levels [13]. After the period of exclusive breastfeeding, the weaning period is also important including the complementary and supplementary foods which are given to the child.

Having a low socioeconomic status can also be a cause for delayed iron supplementations and having decreased access to iron rich food during weaning [4]. Most of the children with anemia were brought to the hospital with complaints for multiple organ systems and were incidentally found to have anemia which correlates to the study done by Singh and Parihar [10] as the majority of the complaints which were commonly found in their study were also found to be under infectious diseases, respiratory system, and gastrointestinal system. This indicates that children with mild or moderate anemia may not be brought to the hospital with complaints regarding anemia. In mild or moderate anemia, most commonly the child will be asymptomatic, hence, subtle symptoms and signs of anemia may not be noticed by the parents or the doctors. This goes to show that a meticulous history and medical examination are important and need to be performed in every child to identify mild or moderate anemia.

\section{CONCLUSION}

The most common causes of nutritional anemia seen in children are iron, Vitamin B12, and folate deficiency, leading to a higher proportion of iron deficiency anemia. This may be because of delayed weaning of the child or starting cow's milk before 6 months of age. Exclusive breastfeeding should be encouraged despite the risk of anemia as it still is beneficial for the child's growth and development. Anemia can be prevented by starting adequate iron supplements and iron-rich food while weaning. Since most of the younger children with mild or moderate anemia might be asymptomatic, a laboratory screening should be done at 12 months of age with appropriate long-term follow-up. Other measures which can be beneficial are appropriate meal programs in schools, providing iron supplementation through iron fortified foods and encouraging regular deworming. It is also important to counsel and educate the parents, especially the mother on effective nutritional practices (iron supplementation during pregnancy) and hygiene measures to prevent the occurrence of anemia in the child.

\section{REFERENCES}

1. National Family Health Survey; c2009. Available from: http://rchiips.org/ nfhs/NFHS-4reports/karnataka.pdf [Last accessed on 2021 Jan 25].

2. Food Security. Drishti Publications. New Delhi: Drishti; Available from: https://www.drishtiias.com/to-the-points/paper3/food- security-1 [Last accessed on 2021 Jan 06].

3. Elizabeth KE. Nutrition and Child Development. $4^{\text {th }}$ ed. Kerala: Paras Medical Publisher; 2010. p. 22-4, 35-8.

4. World Health Organization. Infant and Young Child Feeding; 2021 Available from: www.who.int/health-topics/breastfeeding\#tab=tab_2 [Last accessed on 2021 Jan 25].

5. World Health Organization. Malnutrition. World Health Organization; 2021. Available from: https://www.who.int/news-room/fact-sheets/detail/ malnutrition [Last accessed on 2021 Jan 25].

6. United Nations in India Nutrition and Food Security; 2016. Available from: https://in.one.un.org/un-priority-areas-in-india/nutrition-and-food-security [Last accessed on 2021 Jan 25].

7. National Family Health Survey 5; District Fact Sheet: Bangalore; 2020. Available from: http://rchiips.org/nfhs/NFHS-5_FCTS/KA/Bangalore.pdf [Last accessed on 2021 Jan 02].

8. World Health Organization. Haemoglobin Concentrations for the Diagnosis of Anemia and Assessment of Severity World Health Organization. Geneva: World Health Organization; c2011. Available from: https://www.who.int/ vmnis/indicators/haemoglobin.pdf [Last accessed on 2021 Jan 02].

9. Kanchana, Madhusudan Sr, Ahuja S, Nagaraj N. Prevalence and risk factors in under five year old children in children's hospital. Int J Contemp Pediatr 2018;5:499-502.

10. Singh S, Parihar S. Prevalence of anemia in under five-year-old children: A hospital based study. Int J Contemp Pediatr 2019;6:842-7.

11. Gebreweld A, Ali N, Ali R, Fisha T. Prevalence of anemia and its associated factorsamong children under five years of age attending at Guguftu health center, South Wollo, Northeast Ethiopia. PLoS One 2019;14:e218961.

12. Parkin PC, Maguire JL. Iron deficiency in early childhood. CMAJ 2013; $185: 1237-8$.

13. Marol R, Marol R. Prevalence of anemia in exclusively breastfed full term babies between 3-6 months of age. Int J Contemp Pediatr 2021;8:300-5.

14. Santos RF, Gonzalez ES, Albuquerque EC, Arruda IK, Diniz AD, Figueroa JN, et al. Prevalence of anemia in under five-year-old children in a childrens hospital in Recife, Brazil. Rev Bras Hematol Hemoterapia 2010;33:100-4.

15. Buck S, Rolnick K, Nwaba AA, Eickhoff J, Mezu-Nnabue K, Esenwah E, et al. Longer breastfeeding associated with childhood anemia in rural SouthEastern Nigeria. Int J Pediatr 2019;2019:9457981.

Funding: None; Conflicts of Interest: None Stated.

How to cite this article: Saranappa $\mathrm{S}, \mathrm{Wu} \mathrm{J}$. A clinical study of anemia in children aged 6 months -5 years in a tertiary care center, Bengaluru, Karnataka, India. Indian J Child Health. 2021; 8(10):367-370. 